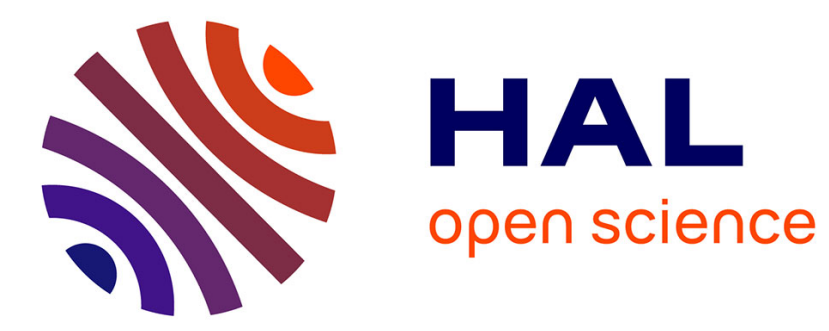

\title{
Hydroamination of ethylene by aniline: catalysis in water
}

Pavel Dub, Mireia Rodriguez-Zubiri, Christine Baudequin, Rinaldo Poli

\section{To cite this version:}

Pavel Dub, Mireia Rodriguez-Zubiri, Christine Baudequin, Rinaldo Poli. Hydroamination of ethylene by aniline: catalysis in water. Green Chemistry, 2010, 12 (8), pp.1392-1396. 10.1039/C004727A . hal-02385300

\section{HAL Id: hal-02385300 \\ https://hal-normandie-univ.archives-ouvertes.fr/hal-02385300}

Submitted on 29 Jul 2021

HAL is a multi-disciplinary open access archive for the deposit and dissemination of scientific research documents, whether they are published or not. The documents may come from teaching and research institutions in France or abroad, or from public or private research centers.
L'archive ouverte pluridisciplinaire HAL, est destinée au dépôt et à la diffusion de documents scientifiques de niveau recherche, publiés ou non, émanant des établissements d'enseignement et de recherche français ou étrangers, des laboratoires publics ou privés. 


\title{
Hydroamination of ethylene by aniline: catalysis in water
}

\author{
Pavel A. Dub, ${ }^{\text {a,b }}$ Mireia Rodriguez-Zubiri, ${ }^{a}$ Christine Baudequin ${ }^{\mathrm{a}}$ and Rinaldo Poli*,a,c \\ Received (in $X X X, X X X)$ Xth $X X X X X X X X X 200 X$, Accepted Xth $X X X X X X X X X 200 X$ \\ First published on the web Xth $X X X X X X X X X 200 X$ \\ ${ }_{5}$ DOI: 10.1039/b000000x
}

\begin{abstract}
The platinum-catalyzed and halide-promoted hydroamination of ethylene with aniline is reported for the first time in the presence of simple sodium halides in water. Compounds $\mathrm{K}_{2} \mathrm{PtX} 4(\mathrm{X}=\mathrm{Cl}$ or $\mathrm{Br}), \mathrm{PtX}_{2}$ or $\mathrm{PtX}_{4}(0.3 \% \mathrm{~mol})$ in the presence of an aqueous solution of excess $\mathrm{NaX}$ and aniline under ethylene pressure ( 25 bar) affords $N$-ethylaniline with $60-85$ turnovers after $10 \mathrm{~h}$ at $150{ }^{\circ} \mathrm{C}$.

10 The best result $(\mathrm{TON}=85$ ) was obtained in the presence of excess $\mathrm{NaBr}$, whereas a slightly lower activity was observed with $\mathrm{NaCl}$ (60 cycles) and practically no activity with $\mathrm{NaF}$ or NaI (2-4 cycles). The reaction also produces $N, N$-diethylaniline (up to 1 cycle) and 2-methylquinoline (up to 8 cycles) as by-products. The influence of added $\mathrm{H}^{+}$and different oxidizing agents was also examined.
\end{abstract}

${ }_{15}$ Keywords: platinum, hydroamination of ethylene, aniline, catalysis in water

\section{Introduction}

Catalytic hydroamination, the direct formation of a new $\mathrm{C}-\mathrm{N}$ bond by addition of the $\mathrm{N}-\mathrm{H}$ bond to an unsaturated $\mathrm{C}=\mathrm{C}$ function in the presence of a catalyst, is a subject of current 20 interest both for fundamental research and for the chemical industry. ${ }^{1-3}$ It is an atom-economical reaction constituting an interesting alternative entry to higher amines, which currently is mostly achieved by the catalyzed condensation of ammonia or amines with alcohols. ${ }^{4}$ Since most primary alcohols are 25 industrially produced from alkenes (hydroformylationhydrogenation sequence), 5,6 the hydroamination process would suppress at least one step and avoid the coproduction of water. The intermolecular version of this reaction with nonactivated olefins is still a great challenge to chemists. ${ }^{2,3}$ The 30 direct reaction of ethene with compounds containing $\mathrm{N}-\mathrm{H}$ bonds (amines, amides, ...) is of particular interest for the large-scale synthesis of ethyl substituted nitrogen compounds.

An interesting catalytic system (in terms of both activity and operating conditions) for the platinum-catalyzed addition 35 of aniline to ethylene was introduced in 2004 by Brunet and co-workers. ${ }^{7}$ Other reports of Pt-based intermolecular hydroamination reactions (mostly of ethylene or norbornene) have subsequently appeared. ${ }^{8-14}$ All these catalytic systems appear to be effective for weakly basic amines such as aryl 40 substituted sulfonamides, carboxamides, and electrondeficient anilines, while they did not lead to a satisfactory conversion for more basic amines. For example, no reaction was observed for the ethylene hydroamination with secondary amines in the presence of $\left[\mathrm{PtCl}_{2}\left(\mathrm{C}_{2} \mathrm{H}_{4}\right)\right]_{2} / \mathrm{PPh}_{3}{ }^{8}$ or for the 45 norbornene hydroamination with aniline in the presence of (COD)Pt(OTf) $2 .{ }^{9}$ The Brunet system, constituted by simple platinum halides $\left(\mathrm{PtX}_{2}{ }^{15}\right.$ or $\left.\mathrm{PtX}_{4}{ }^{12}\right)$ in the presence of a molten halide salt, $n \mathrm{Bu}_{4} \mathrm{PX}$, as a promoter appears the simplest and most effective among the family of platinum catalysts. The

50 initial report focused on the properties of $n \mathrm{Bu} 4 \mathrm{PX}$ as an ionic solvent, ${ }^{7,15}$ but a more detailed study of catalytic activity as a function of halide nature and $\mathrm{X} / \mathrm{Pt}$ ratio revealed that the salt rather functions as an activator through the presence of the coordinating halide anion, ${ }^{12}$ with bromide leading to the 55 highest activity increase for the addition of aniline to ethylene. Catalytic schemes based on the dominant role of $\left[\mathrm{PtBr}_{4}\right]^{2-}$ or $\left[\mathrm{PtBr}_{3}\left(\mathrm{C}_{2} \mathrm{H}_{4}\right)\right]^{-}$have then been proposed. ${ }^{13}, 16$

The Brunet catalyst is already quite simple and robust, because it is made up of commercially available ligandless 60 platinum halides plus an organic halide additive with no need to use organic solvents and was shown to be nearly as efficient when taking no special precaution to remove air from the system. However, we strived to further simplify it by changing the salt additive to a more readily available and less ${ }_{65}$ expensive alkali metal halide, dissolved in water. These are the "greenest" possible conditions that one can imagine for this atom-economical transformation. We were pleased with the results of this investigation, which will be shown in this contribution.

\section{${ }_{70}$ Experimental section}

\section{Methods and Materials.}

$\mathrm{PtCl}_{2}$ (STREM), $\mathrm{PtBr}_{2}$ (Alfa Aesar), $\mathrm{PtCl}_{4}$ (STREM), $\mathrm{PtBr}_{4}$ (STREM), $\mathrm{K}_{2} \mathrm{PtCl}_{4}$ (Alfa Aesar), $\mathrm{K}_{2} \mathrm{PtBr}_{4}$ (Aldrich), $\mathrm{PdBr}_{2}$ (Aldrich), Pt black (STREM), NaF (Alfa Aesar), NaX (X = ${ }_{75} \mathrm{Cl}, \mathrm{Br}$, I Acros Organics), $\mathrm{CuCl}_{2}$ (STREM), and $n \mathrm{Bu}_{4} \mathrm{PBr}$ (Aldrich) were used as received. Benzoquinone (Acros) was resublimed before use. Aniline and 2-methylquinoline (Alfa Aesar), $N$-ethylaniline and $N, N$-diethylaniline (Acros), and $\mathrm{N}, \mathrm{N}$-dibutylaniline (Acros) were distilled under vacuum and 80 kept under argon in the dark. Distilled water was degassed by an argon flow before each experiment. DMSO, DMF (VWR Prolabo) and EtOH (Carlo Erba) were used as received and degassed by an argon flow before experiments. Ethylene (N25) was purchased from Air Liquide. Unless otherwise 85 stated, all the manipulations were performed under argon.

\section{Instumentation}


The GC analyses were performed on a Hewlett-Packard HP 4890 chromatograph equipped with an FID, an HP 3395 integrator and a $30 \mathrm{~m} \mathrm{HP1}$ capillary column. Under the selected operating conditions [helium as carrier gas at $\mathrm{p}=50$ ${ }_{5} \mathrm{kPa}, \mathrm{T}_{\text {start }}=65^{\circ} \mathrm{C}(2 \mathrm{~min}), \Delta \mathrm{T}=6 \% \mathrm{~min}, \mathrm{~T}_{\text {end }}=200^{\circ} \mathrm{C}(20$ min)] the retention times were: $\mathrm{PhNH}_{2}, 7 \mathrm{~min}$; PhNHEt, 11 min; $\mathrm{PhNEt}_{2}, 12 \mathrm{~min}$; quinaldine, $15 \mathrm{~min} ; \mathrm{PhN}(n \mathrm{Bu})_{2}$ (external standard), $21 \mathrm{~min}$. Small amounts of by-products (maximum intensity of $50 \%$ relative to the peak of $\mathrm{PhNEt}_{2}$ ) 10 were eluted after 13, 15, 17 and 18 min. Calibration curves for each compound were obtained using pure samples at several different concentrations. NMR $\left({ }^{1} \mathrm{H}\right.$ and $\left.{ }^{13} \mathrm{C}\left\{{ }^{1} \mathrm{H}\right\}\right)$ investigations were carried out on a Bruker DPX300 spectrometer operating at $300.1 \mathrm{MHz}\left({ }^{1} \mathrm{H}\right)$ and $75.47 \mathrm{MHz}$ ${ }_{15}\left({ }^{13} \mathrm{C}\left\{{ }^{1} \mathrm{H}\right\}\right), \mathrm{D}_{2} \mathrm{O}$ (traces) and $\mathrm{CD}_{2} \mathrm{Cl}_{2}$ (traces) were added for locking purposes for the analysis of the water-rich and organic-rich phases, respectively.

\section{Hydroamination of Ethylene by Aniline}

Catalytic experiments were conducted in a $100 \mathrm{ml}$ stainless 20 steel autoclave without glass liner under magnetic stirring. It was experimentally observed (see Results and Discussion) that the use of glass liners results in inhomogeneous conditions with loss of reproducibility. In a typical procedure, the autoclave was charged with the $\mathrm{Pt}$ compound $\left(\mathrm{PtX}_{2}\right.$, or ${ }_{25} \mathrm{PtX}_{4}$, or $\left.\mathrm{K}_{2} \mathrm{PtX}_{4} ; 0.13 \mathrm{mmol}\right)$ and the desired excess amount of $\mathrm{NaX}$ (see Results and Discussion section), closed, and submitted to vacuum/argon cycles. Degassed water (15 or 5 $\mathrm{ml})$ and then aniline $(4.15 \mathrm{ml}, 45 \mathrm{mmol})$ were added to the autoclave by syringe through a valve equipped with septum 30 and the ethylene pressure adjusted to $25 \mathrm{bar}$ (ca. $100 \mathrm{mmol}$ ). The temperature was then raised to $150^{\circ} \mathrm{C}$. After $10 \mathrm{~h}$, the autoclave was allowed to cool to room temperature and slowly vented. The entire reaction mixture was treated with the external standard ( $N, N$-dibutylaniline) and extracted with 35 dichloromethane (ca. $60 \mathrm{ml}$ ). The organic layer was analyzed by GC and GC-MS. Each run presented in this work was performed at least twice (up to five times for the most relevant results). A statistical analysis of reproducibility gives the following errors for the measured TON values: PhNHEt, \pm 10 ; $40 \mathrm{PhNEt}_{2}$ and quinaldine, \pm 1 .

\section{Results and discussion}

Our study started with a verification of the previously published experimental work. ${ }^{7}$ We found the same results at the qualitative level, with the reaction producing $\mathrm{N}$ 45 ethylaniline (major), $N, N$-diethylaniline (traces) and 2methylquinoline or quinaldine (minor), see Scheme 1. However, the occasional lack of reproducibility encouraged us to test the reaction in the absence of glass liner, yielding reproducibly higher TON, see Table 1 . This phenomenon is 50 attributed to the accumulation of condensed substrate vapours in the small cavity between the glass liner and the autoclave walls, as indeed experimentally observed. As shown in Table 1 , the previously reported decrease of the activity upon increasing the salt amount was confirmed. All subsequent ${ }_{55}$ experiments were therefore run in the absence of glass liner.

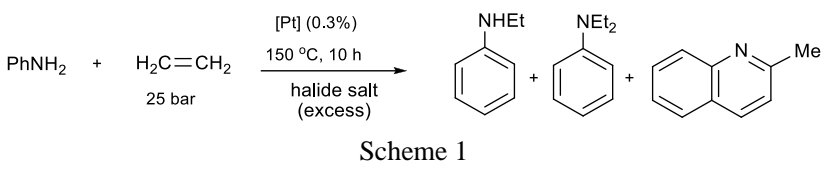

The process was then investigated with aqueous $\mathrm{NaBr}$ in place of $n \mathrm{Bu} 4 \mathrm{PBr}$. This salt was initially selected because the ${ }_{60}$ bromide anion was previously shown to yield the best activities for the tetra- $n$-butylammonium salt series (see introduction). All runs were carried out over $10 \mathrm{~h}$, the same lapse of time used in the previous work with $n \mathrm{Bu}_{4} \mathrm{PBr}^{7}$ The same three products shown in Scheme 1 were again obtained ${ }_{65}$ in roughly the same proportions, with only a marginally lower catalytic activity, see Table 2 , run 3 . Some other organic compounds were also detected in trace amounts $(<0.5 \%)$, among which 1,2,3,4-tetrahydro-2-methylquinoline could be identified on the basis of a GC-MS analysis. Note that exactly 70 the same product composition was previously observed when using $n \mathrm{Bu} 4 \mathrm{PBr}$, underlying the same mechanism. ${ }^{7}$ Note also that no catalysis was observed in the absence of $\mathrm{PtBr}_{2}$ (run 4), and a very low activity was recorded in the presence of $\mathrm{PtBr}_{2}$ but in the absence of $\mathrm{NaBr}$ (run 5). Thus, the activating role of 75 the bromide salt is confirmed for the new catalytic conditions reported here.

Table 1. Pt-catalyzed aniline addition to ethylene in the presence of $n \mathrm{Bu}_{4} \mathrm{Br}^{\mathrm{a}}$

\begin{tabular}{cccccccc} 
run & Salt/Pt & $\begin{array}{c}\text { Glass } \\
\text { liner }\end{array}$ & $\begin{array}{c}\text { PhNHEt } \\
\text { TON }\end{array}$ & TON & $\begin{array}{c}\text { Quinaldine } \\
\text { TON }\end{array}$ & $\begin{array}{c}\text { Conv. } \\
(\%)\end{array}$ & Ref. \\
\hline & 10 & Yes & 130 & 1 & 10 & 40 & 13 \\
& 150 & Yes & 80 & 1 & 10 & 26 & 7 \\
1 & 10 & No & 140 & 3 & 15 & 45 & $\mathrm{~b}$ \\
2 & 150 & No & 100 & 1 & 15 & 33 & $\mathrm{~b}$
\end{tabular}

80 a Conditions: $\operatorname{PtBr}_{2}(0.13 \mathrm{mmol})$, aniline $(4.15 \mathrm{~mL})$, ethylene (25 bar at $\mathrm{RT}), n \mathrm{Bu}_{4} \mathrm{Br}, \mathrm{T}=150^{\circ} \mathrm{C}, \mathrm{t}=10 \mathrm{~h}$. ${ }^{\mathrm{b}} \mathrm{This}$ work.

Table 2. Pt-catalyzed aniline addition to ethylene in the presence of aqueous $\mathrm{NaBr}$. $^{\text {a }}$

\begin{tabular}{ccccccc} 
run & Salt/Pt & Time (h) PhNHEt & $\mathrm{PhNEt}_{2}$ & $\begin{array}{c}\text { Quinaldine } \\
\text { TON }\end{array}$ & $\begin{array}{c}\text { Conv. } \\
\text { TON }\end{array}$ & $\begin{array}{c}\text { TON } \\
(\%)\end{array}$ \\
\hline 3 & 150 & 10 & 85 & 1 & 8 & 27 \\
4 & $\mathrm{~b}$ & 10 & $\sim 0.6$ & 0 & 1 & 0.5 \\
5 & 0 & 10 & 5 & $\sim 0.1$ & 1 & 1.7 \\
6 & 150 & 24 & 90 & 1 & 8 & 28 \\
7 & 150 & 48 & 90 & 1 & 8 & 28
\end{tabular}

aConditions: $\mathrm{PtBr}_{2}(0.13 \mathrm{mmol})$, aniline $(4.15 \mathrm{ml})$, ethylene $(25 \mathrm{bar}$ at $\left.{ }_{85} \mathrm{RT}\right), \mathrm{NaBr}$ (150 equiv) in water $(15 \mathrm{~mL}), \mathrm{T}=150^{\circ} \mathrm{C}$. ${ }^{\mathrm{b}} \mathrm{Same}$ amount of $\mathrm{NaBr}$ as in run 3, in the absence of $\mathrm{PtBr}_{2}$.

One question that needs to be addressed is the effect of the reaction time and of possible catalyst deactivation. The Brunet catalyst was already shown to deposit inactive metallic $\mathrm{Pt}$ 90 with activites reaching a pleateau after ca. $10 \mathrm{~h}$ : the TON for the $N$-ethylaniline product were 37 after $1 \mathrm{~h}, 64$ after $2.5 \mathrm{~h}, 72$ after $5 \mathrm{~h}$ and 80 after $10 \mathrm{~h}^{7}$ We have therefore tested our system at longer reaction time (runs 6 and 7). Activites were essentially the same as after $10 \mathrm{~h}$, confirming that the catalyst 95 is totally deactivated. Visual inspection of the reaction mixture confirms the total convertion of the catalyst into the metallic state. The discharged reaction mixture consists of a two phase system with a colorless aqueous phase and a black stable suspension in the organic layer. 
We next proceeded to investigate the influence of the $\mathrm{NaBr}$ amount. Runs 3 and 4 involved $\sim 2 \mathrm{~g}$ of $\mathrm{NaBr}$, whereas $>10 \mathrm{~g}$ can be dissolved in the same amount of water at room temperature. It should be remarked that aniline is also ${ }_{5}$ partially soluble in water $\left(3.6 \mathrm{~g} / 100 \mathrm{~mL} \text { at } 20^{\circ} \mathrm{C}\right)^{17}$ and this certainly has an influence on the $\mathrm{NaBr}$ solubility. At the reaction temperature of $150^{\circ} \mathrm{C}$, the water/aniline miscibility is expected to significantly increase and the $\mathrm{NaBr}$ solubility may also increase, but a miscibility study of the water/aniline/ $\mathrm{NaBr}$ 10 ternary system does not appear available. We were only able to find a phase diagram of the water-aniline mixture at $1 \mathrm{~atm}$, showing equilibrium between two phases containing respectively $16 \%$ and $78 \%$ aniline at $150^{\circ} \mathrm{C}$. The presence of $\mathrm{NaBr}$ in large quantities is expected to render the two liquids 15 less miscible, thus a biphasic system is certainly present under catalytic conditions. In addition, the system is further complicated by the presence of ethylene. A phase diagram investigation for this complex mixture is beyond the scope of the present study. The catalytic results obtained in the 20 presence of variable $\mathrm{NaBr}$ amounts are presented in Table 3.

Table 3. Pt-catalyzed aniline addition to ethylene. Influence of the $\mathrm{NaBr}$ and water amounts. ${ }^{\mathrm{a}}$

\begin{tabular}{ccccccc} 
run & Salt/Pt & $\begin{array}{c}\text { Water } \\
(\mathrm{mL})\end{array}$ & $\begin{array}{c}\text { PhNHEt } \\
\text { TON }\end{array}$ & TON & $\begin{array}{c}\text { Quinaldine } \\
\text { TON }\end{array}$ & $\begin{array}{c}\text { Conv. } \\
(\%)\end{array}$ \\
\hline 8 & 10 & 15 & 24 & $\sim 0.3$ & 3 & 8 \\
9 & 100 & 15 & 64 & 1 & 6 & 20 \\
10 & 200 & 15 & 45 & 1 & 5 & 15 \\
11 & 500 & 15 & 27 & 6 & 3 & 10 \\
12 & 10 & 5 & 62 & 2 & 7 & 20 \\
13 & 50 & 5 & 74 & 3 & 8 & 24 \\
14 & 100 & 5 & 61 & 3 & 8 & 21 \\
15 & 150 & 5 & 31 & 2 & 7 & 11
\end{tabular}

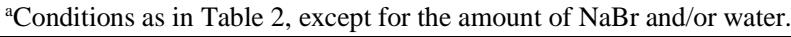

25 It is clearly seen that upon increasing the $\mathrm{NaBr}$ amount beyond 150 equivalents the total activity decreases (runs 10 and 11), which is in agreement with the results obtained in the presence of $n \mathrm{Bu}_{4} \mathrm{PBr}$ (Table 1), while the selectivity tends to shift in favour of the $N, N$-diethylamine product. Reducing the 30 amount of salt also resulted in loss of activity (runs 8 and 9). This behaviour is different from that of the $n B \mathrm{Bu}_{4} \mathrm{PBr}$ promoter, for which a higher activity was observed with a $\mathrm{Br} / \mathrm{Pt}$ ratio of 10 (Table 1 ). The best activity remains that observed in run 3 (Table 2) with 150 equivalents of $\mathrm{NaBr}$ per $35 \mathrm{Pt}$. Note also that the entire $\mathrm{NaBr}$ amount was found dissolved (not observed as a solid) in all the recovered mixtures. Next, we have tested the influence of the amount of water in the medium. Reducing the amount of water from 15 to $5 \mathrm{~mL}$ for either a tenfold (run 12) or a fifty-fold (run 13) excess of ${ }_{40} \mathrm{NaBr}$ gave a higher activity, close to that of run 3 in Table 2. However, upon further increasing the $\mathrm{NaBr}$ amount the overall activity decreases (runs 14, 15). In this case the best activity was found with a fifty-fold excess.

The influence of $\mathrm{H}^{+}$on the reaction was also examined. 45 This study was justified by the previous report of a positive effect of catalytic amounts of strong acids (3 equiv per $\mathrm{Pt}$ ), which would be levelled in strength to anilinium in the reaction medium. ${ }^{7}$ The same phenomenon might be expected under the present catalytic conditions, since aniline is a
50 stronger base than water. The catalytic results, see Table 4 , show that acids do not have a promoting effect under the present conditions. Rather, a small but significant decrease of activity was revealed in the presence of excess acid. One equivalent of acid (either $\mathrm{HBr}$ or $\mathrm{CF}_{3} \mathrm{COOH}$ ) has essentially 55 no effect on the activity ( $c f$. runs 16 and 20 with run 3 ), but further acid addition (runs 17-19, 21) has a negative effect on the activity. Note also that the reaction selectivity changes, the TON decreasing for ethylaniline and quinaldine and increasing for diethylaniline as the amount of $\mathrm{HBr}$ increases 60 (runs 16-19).

Table 4. Pt-catalyzed aniline addition to ethylene. Influence of added acids. ${ }^{\mathrm{a}}$

\begin{tabular}{|c|c|c|c|c|c|}
\hline run & $\operatorname{acid}(\mathrm{eq})$ & $\begin{array}{c}\text { PhNHE } \\
\text { TON }\end{array}$ & $\begin{array}{c}\mathrm{PhNEt}_{2} \\
\text { TON }\end{array}$ & $\begin{array}{c}\text { Quinaldine } \\
\text { TON }\end{array}$ & $\begin{array}{c}\text { Conv. } \\
(\%)\end{array}$ \\
\hline 16 & $\mathrm{HBr}(1)$ & 88 & 2 & 8 & 28 \\
\hline 17 & $\operatorname{HBr}(3)$ & 78 & 3 & 7 & 25 \\
\hline 18 & $\mathrm{HBr}(5)$ & 41 & 4 & 5 & 14 \\
\hline 19 & $\mathrm{HBr}(20)$ & 26 & 9 & 3 & 11 \\
\hline 20 & $\mathrm{CF}_{3} \mathrm{COOH}(1)$ & 79 & 2 & 8 & 25 \\
\hline 21 & $\mathrm{Et}_{2} \mathrm{O} \cdot \mathrm{HBF}_{4}(3)$ & 51 & 4 & 6 & 17 \\
\hline
\end{tabular}

${ }^{\text {a }}$ Conditions as in Table 2, run 3, except for the acid addition.

${ }_{65}$ We have also investigated the effect of specific oxidants as additives, in an attempt to avoid the deposition of $\mathrm{Pt}^{0}$ or oxidize it back to an active form of the catalyst. $\mathrm{Pt}^{0}$ is not active for the ethylene hydroamination: a test run in the presence of the same catalytic amount of platinum black gave 70 only a $0.6 \%$ conversion with ca. 1 TON for ethylaniline and 1 TON for quinaldine (essentially the same results as in the control without $\mathrm{Pt}$ compound, run 4). Agents such as benzoquinone, ${ }^{18-20} \mathrm{O}_{2} / \mathrm{CuCl}_{2},{ }^{21-23}$ or $\mathrm{O}_{2} / \mathrm{DMSO}^{24}$ were shown to oxidize $\mathrm{Pd}^{0}$ for related catalytic systems. The results are 75 shown in Table 5 . We first carried out the reaction in the presence of air (run 22), yielding approximately half the activity recorded under argon (run 3). Further addition of $\mathrm{CuCl}_{2}$ and $\mathrm{HCl}$ to the system (conditions of the Wacker process) further decreases the activity. The negative effect of 80 strong acids has been pointed out above (runs 16-19), but note that the presence of $\mathrm{CuCl}_{2}$ also seems to have a negative effect in this case, because the activity in the presence of $\mathrm{CuCl}_{2}$ alone is lower than that in the presence of $\mathrm{HCl}$ alone (run 24), and this does not greatly depend upon whether the 85 catalysis is run under argon (run 25) or in the presence of air (run 26). The presence of benzoquinone or DMSO/air also does not improve the results (runs 27 and 28). The activity in the presence of DMSO under argon (run 29) is slightly better than in air (run 28), but still lower than that of run 3 in the 90 absence of DMSO. The formation of a $\mathrm{Pt}^{0}$ deposit was still observed in all these catalytic runs.

Table 5. Pt-catalyzed aniline addition to ethylene. Influence of oxidants. ${ }^{\mathrm{a}}$

\begin{tabular}{cccccc} 
run & additive (eq) & $\begin{array}{c}\text { PhNHEt } \\
\text { TONNEt }\end{array}$ & Quinaldine Conv. \\
& & TON & TON & $(\%)$ \\
\hline 22 & $-^{-}$ & 43 & 2 & 5 & 14 \\
23 & $\mathrm{CuCl}_{2}(5), \mathrm{HCl}(5)^{\mathrm{b}}$ & 24 & 2 & 2 & 8 \\
24 & ${\mathrm{HCl}(5)^{\mathrm{b}}}$ & 39 & 2 & 6 & 13 \\
25 & $\mathrm{CuCl}_{2}(5)$ & 15 & 1 & 1 & 5 \\
26 & $\mathrm{CuCl}_{2}(5)^{\mathrm{b}}$ & 20 & 2 & 3 & 7 \\
27 & benzoquinone (10) $^{2}$ & 69 & 1 & 7 & 22
\end{tabular}


${ }^{a}$ Conditions as in Table 2, run 3, except for the additive. ${ }^{\mathrm{b}}$ Experiment run without removing air from the aniline and from the autoclave head space.

As mentioned above, the catalytic reaction most certainly occurs in a biphasic system at $150{ }^{\circ} \mathrm{C}$. Thus, we have explored 5 the effect of the addition of compatibilizing solvents, in an attempt to homogenise the system. The addition of bipolar aprotic solvents such as DMF or DMSO (ca. $7 \mathrm{ml}$ ) completely homogenise the system aniline-water- $\mathrm{NaBr}(150 \mathrm{eq})$ at room temperature. The catalytic results, see Table 6 , show complete 10 or nearly complete deactivation by DMSO (run 30) or DMF (run 31), respectively. It should be noted that DMSO and DMF are also strong ligands. In a previous study, we have shown that isolated Pt-aniline complexes lose the aniline and/or ethylene ligand upon dissolution in DMSO. ${ }^{16}$ On the 15 other hand, heating the same complexes in DMF leads to decomposition. Thus, although DMSO and DMF are able to homogenise the system, they probably lead to other stable and catalytically inactive $\mathrm{Pt}$ complexes. Conversely, the addition of EtOH leads to a marginally lower activity ( $c f$. run 32 and 20 run 3$)$.

Table 6. Pt-catalyzed aniline addition to ethylene. Influence of added solvents. ${ }^{\mathrm{a}}$

\begin{tabular}{cccccc} 
run & $\begin{array}{c}\text { additive } \\
(\mathrm{mL})\end{array}$ & $\begin{array}{c}\mathrm{PhNHEt}^{2} \\
\text { TON }\end{array}$ & TON & $\begin{array}{c}\text { Quinaldine } \\
\text { TON }\end{array}$ & $\begin{array}{c}\text { Conv. } \\
(\%)\end{array}$ \\
\hline 30 & DMSO (7) & 0 & 0 & 0 & 0 \\
31 & DMF (7) & 3 & 0 & 1 & 1 \\
32 & EtOH (2) & 72 & 2 & 8 & 23
\end{tabular}

${ }^{a}$ Conditions as in Table 2, run 3, except for the additive.

25 Another important point to investigate was the influence of the halide nature. We have tested the entire series of sodium halides $\mathrm{NaX}$, including the fluoride not previously investigated along the $n \mathrm{Bu} 4 \mathrm{PX}$ series. ${ }^{7}, 10,12$ The results, reported in Table 7 , show that practically no reaction takes 30 place when $\mathrm{X}=\mathrm{F}$ or $\mathrm{I}$. The highest activities were observed in the middle of the Group for $\mathrm{X}=\mathrm{Br}$ and $\mathrm{Cl}$, with $\mathrm{Br}$ being slightly better. These results perfectly parallel those previously established for the $n \mathrm{Bu}_{4} \mathrm{PX}$ system.

35 Table 7. Pt-catalyzed aniline addition to ethylene. Influence of the halogen in $\mathrm{NaX} .^{\mathrm{a}}$

\begin{tabular}{cccccc} 
run & salt & $\begin{array}{c}\mathrm{PhNHEt} \\
\text { TON }\end{array}$ & TON & $\begin{array}{c}\text { Quinaldine } \\
\text { TON }\end{array}$ & $\begin{array}{c}\text { Conv. } \\
(\%)\end{array}$ \\
\hline 33 & $\mathrm{NaF}$ & 2 & 0 & 1 & 1 \\
34 & $\mathrm{NaCl}$ & 60 & 1 & 5 & 19 \\
35 & $\mathrm{NaI}$ & 4 & $\sim 0.3$ & 2 & 2
\end{tabular}

${ }^{a}$ Conditions as in Table 2, run 3, except for the nature of $\mathrm{NaX}$.

Finally, we have tested other source of Pt different from $\mathrm{PtBr}_{2}$, namely $\mathrm{K}_{2} \mathrm{PtX}_{4}, \mathrm{PtX}_{4}(\mathrm{X}=\mathrm{Cl}$ or $\mathrm{Br})$ or $\mathrm{PtX}_{2}(\mathrm{X}=\mathrm{Cl}, \mathrm{I})$, 40 and also $\mathrm{PdBr}_{2}$. According to the proposed mechanism, ${ }^{13,16}$ all the $\mathrm{Pt}$ precatalysts should yield $\left[\mathrm{PtBr}_{4}\right]^{2-}$ as the dominant species in the presence of excess $\mathrm{NaBr}$, or $\left[\mathrm{PtBr}_{3}\left(\mathrm{C}_{2} \mathrm{H}_{4}\right)\right]^{-}$in the presence of $\mathrm{C}_{2} \mathrm{H}_{4} \cdot{ }^{16}$ Furthermore, $\mathrm{PtX}_{4}$ could be easily reduced to the same $\mathrm{Pt}^{\mathrm{II}}$ complexes under the catalytic 45 conditions, for example by ethylene to form $\mathrm{CH}_{2} \mathrm{BrCH}_{2} \mathrm{Br}$. Indeed, compounds $\mathrm{PtBr}_{2}, \mathrm{PtBr}_{4}$ and $\mathrm{PtCl}_{4}$ were previously shown to have essentially the same catalytic activity in the presence of the same excess amount of $n \mathrm{Bu}_{4} \mathrm{PBr}^{12}$ As can be seen from the results in Table 8 , the different Pt compounds 50 also give essentially identical results under the new conditions reported in this contribution. Only marginally lower activities were obtained with $\mathrm{PtCl}_{2}$ (run 38), perhaps because it slowly decomposes upon standing in air and a partially impure sample may have been used. Much poorer results were also 55 obtained with $\mathrm{PtI}_{2}$ (run 39), possibly for similar reasons.

A last catalytic run was performed with $\mathrm{PdBr}_{2}$ (run 42). Both platinum(II) and palladium(II) complexes activate olefins toward nucleophilic attack, but in contrast to their $\mathrm{Pd}(\mathrm{II})$ counterparts, $\mathrm{Pt}$ (II) alkyl complexes are less prone to $\beta$ ${ }_{60}$ hydride elimination, whereas they maintain reactivity toward protonolysis. Thus, Pd systems resulting from amine nucleophilic addition to coordinated ethylene usually prefer to undergo oxidative amination. 1, 20, 25 However, run 42 led to essentially no reaction. Neither the expected hydroamination 65 products nor the oxidative amination products were detected by either gas chromatography or ${ }^{1} \mathrm{H}$ NMR on both the organic and the aqueous phases (a few small and unassigned resonances corresponded to $<0.5 \%$ of aniline consumption).

70 Table 8. Catalyzed aniline addition to ethylene. Influence of the pre-catalyst nature. ${ }^{a}$

\begin{tabular}{cccccc} 
run & {$[\mathrm{Pt}]$} & $\begin{array}{c}\text { PhNHEt } \\
\text { TON }\end{array}$ & TON & $\begin{array}{c}\mathrm{PhNt}_{2} \\
\text { Quinaldine }\end{array}$ & $\begin{array}{c}\text { Conv. } \\
(\%)\end{array}$ \\
\hline 36 & $\mathrm{~K}_{2} \mathrm{PtCl}_{4}$ & 86 & 1 & 8 & 27 \\
37 & $\mathrm{~K}_{2} \mathrm{PtBr}_{4}$ & 81 & 1 & 7 & 25 \\
38 & $\mathrm{PtCl}_{2}$ & 70 & 1 & 8 & 23 \\
39 & $\mathrm{PtI}_{2}$ & 19 & 1 & 2 & 7 \\
40 & $\mathrm{PtCl}_{4}$ & 80 & 2 & 8 & 26 \\
41 & $\mathrm{PtBr}_{4}$ & 76 & 3 & 6 & 24 \\
42 & $\mathrm{PdBr}_{2}$ & 1 & 0 & $\sim 0.3$ & 0.4
\end{tabular}

${ }^{\text {a }}$ Conditions as in Table 2, run 3, except for the nature of the pre-catalyst.

An interesting question concerns the possible nucleophilic addition of water to coordinated ethylene. Such reactivity 75 would result in parallel catalytic processes (formation of ethanol by protonolysis with regeneration of $\mathrm{Pt}^{\mathrm{II}}$, although the reverse process has rather been shown to be favored ${ }^{26}$ ) or stoichiometric processes (formation of acetaldehyde by $\beta-\mathrm{H}$ elimination with formation of $\mathrm{Pt}^{0}$ as in the Pd-catalyzed ${ }_{80}$ Wacker process), see Scheme 2. The latter events might in fact rationalize the slightly lower TON (faster catalytic deactivation) of this aqueous catalytic system relative to the Brunet system. Note that, although no direct nucleophilic attack of $\mathrm{Pt}^{\mathrm{II}}$-coordinated olefines by water or alcohols has 85 been reported under neutral conditions, ${ }^{27}$ both ethanol and acetaldehyde were previously observed from the reaction of $\mathrm{Pt}^{\mathrm{II}}$-ethylene derivatives upon standing in water and ethylene glycol may also be formed in the presence of oxidants. ${ }^{28-32}$ In an aqueous aniline environment, it is also envisageable that 90 acetaldehyde may be present as the hydrate $\mathrm{CH}_{3} \mathrm{CH}(\mathrm{OH})_{2}$ or transformed to the imine $\mathrm{CH}_{3} \mathrm{CH}=\mathrm{NPh}$. In order to verify whether any of these products are formed, an NMR $\left({ }^{1} \mathrm{H}\right.$ and $\left.{ }^{13} \mathrm{C}\left\{{ }^{1} \mathrm{H}\right\}\right)$ analysis of both the aqueous and organic phases was performed for runs 6 and 7. In addition to the recognizable 95 resonances of aniline and the three observed products (Scheme 1), other small resonances were indeed visible in the 
methyl proton region ( $\delta$ ca. $1.8,1.4$ and 1.3 ), and only in the organic phase. Integration of these resonances, however, indicated that they correspond to $<1$ TON. Thus, even assuming that one of these resonances belong to ethanol, we 5 can conclude that the catalyzed ethylene hydration is much less efficient than the hydroamination by aniline. The possible formation of a small stoichiometric amount of $\mathrm{CH}_{3} \mathrm{CHO}$, $\mathrm{CH}_{3} \mathrm{CH}=\mathrm{NPh}$, or other products of further reactions cannot be excluded and it may indeed contribute to faster catalyst 10 deactivaton.

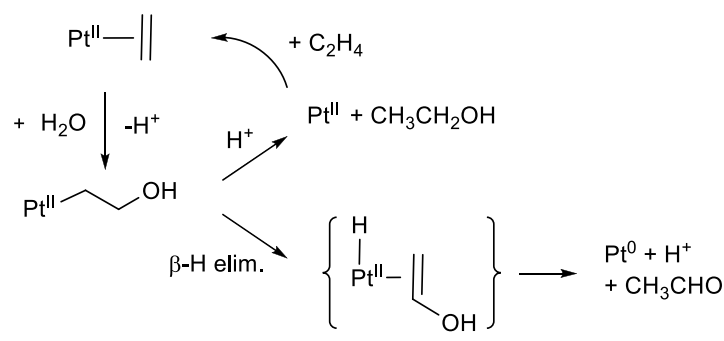

Scheme 2

\section{Conclusions}

15 The efficiency and potential of the Pt-catalysed ethylene hydroamination by aniline under green operating conditions ( $\mathrm{NaBr} /$ water as additive) has been demonstrated. The optimized conditions (run 3 in Table 2) lead to about 85 catalytic turnovers in $10 \mathrm{~h}$. Although the catalytic activity, in 20 terms of TON, is ca. $44 \%$ lower than the system operating with $n \mathrm{Bu}_{4} \mathrm{PBr}$ and without water under identical conditions, this new system represents a valuable gain in terms of operational simplicity and environmental impact, because the $n \mathrm{Bu} 4 \mathrm{PBr}$ salt can be replaced by the much more accessible, 25 less toxic, ${ }^{33}, 34$ and water-soluble $\mathrm{NaBr}$. New mechanistic information is also given by the lack of a major inhibiting effect of water or ethanol, whereas the presence of large amounts of DMF and DMSO results in a dramatic decrease of catalytic activity, as was already shown earlier for phosphine 30 ligands. $^{7}$ The absence of significant amounts of ethanol in the reaction products demonstrates that hydration is not competitive relative to the addition of the aniline $\mathrm{N}-\mathrm{H}$ bond, whereas possible stoichiometric Wacker-type processes leading to $\mathrm{Pt}$ reduction may rationalize the slightly lower 35 performance of the acqueous system relative to $\mathrm{PtBr}_{2} / n \mathrm{Bu} 4 \mathrm{PBr}$. Higher turnovers cannot be achieved because of complete catalyst deactivation. A future challenge will be to engineer a catalyst for which this deactivation process is retarded or eliminated.

\section{Acknowledgement.}

We acknowledged financial support from the CNRS through the GDRE "Homogeneous Catalysis for Sustainable Development" and from the RFBR through the bilateral grant № 08-03-92506. P.A.D. is recipient of a Ph.D. fellowship 45 from the French MENESR (Ministère de l'Éducation Nationale, de l'Enseignement Supérieur et de la Recherche).
${ }^{a}$ CNRS; LCC (Laboratoire de Chimie de Coordination); Université de Toulouse; UPS, INPT; 205, route de Narbonne, F-31077 Toulouse,

50 France. Fax: +33 561553003; Tel:+33 561333173; E-mail:

rinaldo.poli@lcc-toulouse.fr

${ }^{b}$ A. N. Nesmeyanov Institute of Organoelement Compounds, Russian

Academy of Sciences, Vavilov Street 26, 119991 Moscow, Russia

${ }^{c}$ Institut Universitaire de France, 103, bd Saint-Michel, 75005 Paris, 55 France

1 T. E. Müller and M. Beller, Chem. Rev., 1998, 98, 675.

2 J.-J. Brunet and D. Neibecker, in 'Catalytic Heterofunctionalization', ed. A. Togni and H. Grützmacher, Weinheim, 2001.

3 T. E. Müller, K. C. Hultzsch, M. Yus, F. Foubelo, and M. Tada,

$60 \quad$ Chem. Rev., 2008, 108, 3795.

4 K. Visek, 'Kirk-Othmer Encyclopedia of Chemistry and Technology', Wiley \& Sons, 2003.

5 S. A. Lawrence, 'Amines', Cambridge University Press, 2004.

6 J. Falbe, 'New Syntheses with Carbon Monoxide', Springer Verlag, 651980

7 J. J. Brunet, M. Cadena, N. C. Chu, O. Diallo, K. Jacob, and E. Mothes, Organometallics, 2004, 23, 1264.

8 X. Wang and R. A. Widenhoefer, Organometallics, 2004, 23, 1649.

9 D. Karshtedt, A. T. Bell, and T. D. Tilley, J. Am. Chem. Soc., 2005, $70 \quad$ 127, 12640

10 J. J. Brunet, N. C. Chu, and O. Diallo, Organometallics, 2005, 24, 3104.

11 S. Anguille, J.-J. Brunet, N. C. Chu, O. Diallo, C. Pages, and S. Vincendeau, Organometallics, 2006, 25, 2943.

75 M. Rodriguez-Zubiri, S. Anguille, and J.-J. Brunet, J. Mol. Catal. A, 2007, 271, 145.

13 J.-J. Brunet, N.-C. Chu, and M. Rodriguez-Zubiri, Eur. J. Inorg. Chem., 2007, 4711.

14 J. L. McBee, A. T. Bell, and T. D. Tilley, J. Am. Chem. Soc., 2008, 130, 16562 .

15 J. J. Brunet, N. C. Chu, O. Diallo, and E. Mothes, J. Mol. Catal. A, 2003, 198, 107.

16 P. A. Dub, M. Rodriguez-Zubiri, J.-C. Daran, J.-J. Brunet, and R. Poli, Organometallics, 2009, 28, 4764-4777.

${ }_{85} 17$ W. Arlt, M. E. A. Macedo, P. Rasmussen, and J. M. Sorensen, 'Liquid-Liquid Equilibrium Data Collection', Dechema Chemistry Data Series, 1997.

18 L. S. Hegedus, G. F. Allen, and E. L. Waterman, J. Am. Chem. Soc., 1976, 98, 2674.

9019 L. S. Hegedus, G. F. Allen, J. J. Bozell, and E. L. Waterman, J. Am. Chem. Soc., 1978, 100, 5800.

20 L. S. Hegedus, Angew. Chem., Int. Ed. Engl., 1988, 27, 1113.

21 R. F. Heck, 'Palladium Reagents in Organic Synthesis', Academic Press, 1985.

9522 L. S. Hegedus, in 'Comprehensive Organic Synthesis', ed. B. M. Trost and I. Fleming, 1991, 4, 551.

23 J. Tsuji, 'Palladium Reagents and Catalysts, Innovations in Organic Synthesis', Wiley \& Sons, 1995.

24 See ref. 1, and references cited therein.

10025 V. I. Timokhin, N. R. Anastasi, and S. S. Stahl, J. Am. Chem. Soc., 2003, 125, 12996.

26 F. R. Hartley, Inorg. Chim. Acta, 1971, 5, 197.

27 M. Benedetti, F. P. Fanizzi, L. Maresca, and G. Natile, Chem. Commun., 2006, 1118.

\section{Notes and references}


28 G. A. Luinstra, L. Wang, S. S. Stahl, J. A. Labinger, and J. E.

Bercaw, J. Organomet. Chem., 1995, 504, 75.

29 A. C. Hutson, M. R. Lin, N. Basickes, and A. Sen, J. Organomet. Chem., 1995, 504, 69.

$5_{5}^{30}$ N. Basickes, A. C. Hutson, A. Sen, G. P. A. Yap, and A. L. Rheingold, Organometallics, 1996, 15, 4116.

31 D. S. Helfer and J. D. Atwood, Organometallics, 2004, 23, 2412.

32 R. S. Pryadun and J. D. Atwood, Organometallics, 2007, 26, 4830.

33 P. J. Scammells, J. L. Scott, and R. D. Singer, Aust. J. Chem., 2005,

$10 \quad \mathbf{5 8}, 155$.

34 J. S. Torrecilla, J. Garcia, E. Rojo, and F. Rodriguez, Journal of Hazardous Materials, 2009, 164, 182. 